\title{
REFLEXÕES ACERCA DO CONCEITO DE TECNOLOGIA EM UM MINICURSO VIRTUAL
}

Sandra Letícia Schroeder Iglesias ${ }^{1}$, Silvana Aparecida Guietti ${ }^{2}$, Maria Luisa Furlan Costa ${ }^{2}$, Patrícia L.L. Mertzig Gonçalves de Oliveira ${ }^{3}$, Camila Tecla Mortean Mendonça ${ }^{4}$.

${ }^{1}$ Secretaria de Educação do Estado do Paraná, Guarapuava, PR. ${ }^{2}$ Universidade Estadual de Maringá - UEM, Departamento de Fundamentos da Educação, Maringá, PR. ${ }^{3}$ Universidade do Oeste Paulista - UNOESTE, Faculdade de Arte Ciências Letras e Educação de Presidente Prudente, Presidente Prudente, SP. ${ }^{4}$ Centro Universitário Cesumar, UNICESUMAR, PR. Maringá, PR. E-mail: sandraletigle@hotmail.com.

\section{RESUMO}

Mediante a função que a tecnologia tem assumido no campo da Educação, principalmente quando se torna tema central para a Educação a Distância (EaD), observamos ser necessária uma reflexão mais cuidadosa sobre o tema. Assim ofertamos um minicurso para o I Simpósio Virtual sobre Tecnologias Educacionais da Universidade Estadual de Maringá em 2016. O minicurso foi desenvolvido no AVA Moodle e divulgado à professores, tutores, acadêmicos de graduação e de pós-graduação. Para tanto, apresentamos algumas considerações a partir dos estudos realizados por Álvaro Vieira Pinto (1909-1987) no livro O Conceito de Tecnologia (2005). Ao observarmos as interações feitas pelos participantes no decorrer do minicurso, percebemos que muitos compreenderam como o autor esboçou o conceito de tecnologia e puderam refletir sobre como o esclarecimento do conceito ou ainda, a falta dele, podem alterar as propostas pedagógicas e o desenvolvimento de cursos ofertados na modalidade a distância.

Palavras-chave: Tecnologia; Álvaro Vieira Pinto; Educação a Distância. Simpósio virtual.

\section{REFLECTIONS ABOUT THE CONCEPT OF TECHNOLOGY IN A VIRTUAL SHORT DURATION COURSE}

\begin{abstract}
Due to the role that technology has played in the field of Education, especially when it becomes the central theme for distance education $(E a D)$, we observe a more careful reflection on the subject. Thus we offer a short duration course for the 1st Virtual Symposium on Educational Technologies of the State University of Maringá in 2016. The mini-course was developed in AVA Moodle and disclosed to teachers, tutors, undergraduate and graduate students. some considerations from the studies carried out by Álvaro Vieira Pinto (1909-1987) in the book The Concept of Technology (2005) .In observing the interactions made by the participants in the course of the mini-course, we realized that many understood how the author outlined the concept of technology and could reflect on how the clarification of the concept or, in the absence of it, can alter the pedagogical proposals and the development of courses offered in the distance modality. Keywords: Technology; Álvaro Vieira Pinto; Distance Education. Virtual Symposium.
\end{abstract}




\section{INTRODUÇÃO}

As tecnologias sempre fizeram parte do cotidiano das pessoas, sejam elas de cidades pequenas ou grandes, de países considerados desenvolvidos ou subdesenvolvidos. Em todas as épocas da história, a humanidade produziu e produz invenções tecnológicas que vem sendo adotadas e naturalizadas. Na atualidade, contamos com uma quantidade cada vez maior de artefatos tecnológicos principalmente aqueles voltados para a área da informação e da comunicação os quais estão promovendo novas e diferentes interações entre os sujeitos na sociedade.

Sobre o papel que a tecnologia tem assumido na cotidianidade, com destaque para as Tecnologias da Informação e Comunicação (TIC), acreditamos ser necessária uma reflexão mais cuidadosa, principalmente quando esse tema se torna central para a Educação a Distância (EaD).

Entendendo que esse assunto se consubstancia em importante objeto de investigação desenvolvido pelo Grupo de Pesquisa Educação a Distância e Tecnologias Educacionais (GPEaDETC/CNPq) da Universidade Estadual de Maringá (UEM), nós organizamos um projeto para a oferta de um minicurso que teve como título "O conceito de tecnologia: as contribuições de Álvaro Vieira Pinto" que, após sua aprovação, integrou o I Simpósio Virtual sobre Tecnologias Educacionais da UEM ocorrido em 2016.

O minicurso foi desenvolvido no Ambiente Virtual de Aprendizagem/Moodle e ofertado à professores, tutores, acadêmicos de graduação e de pós-graduação. Para tanto, foi organizado uma série de materiais de estudo envolvendo textos e vídeos cujo objetivo era discorrer sobre o conceito de tecnologia e proporcionar aos participantes um espaço de reflexão sobre esse conceito e sua presença na educação.

Assim, apresentamos relevantes considerações acerca da temática a partir dos estudos realizados por Álvaro Vieira Pinto (1909-1987) no 1 o volume do livro O Conceito de Tecnologia (2005) partindo do pressuposto que a referida obra é de grande valia para as discussões atuais sobre tecnologia.

Com intuito de obter uma melhor compreensão dos resultados que a pesquisa e o minicurso nos proporcionou consideramos importante, num primeiro momento, apresentar alguns dados bibliográficos desse intelectual brasileiro, com vistas à compreensão do contexto de produção do seu pensamento. Na sequência, discutimos os pressupostos que fundamentam a formulação do conceito de tecnologia apresentado por Pinto (2005) e, por fim, explicitamos como se deu a oferta do minicurso intitulado: O conceito de tecnologia: as contribuições de Álvaro Vieira Pinto, no âmbito do I Simpósio Virtual sobre Tecnologias Educacionais, da UEM, em 2016.

\section{METODOLOGIA}

De caráter teórico e bibliográfico, o artigo abordará algumas reflexões a respeito do conceito de tecnologia na perspectiva de Pinto (2005) para subsidiar algumas inserções feitas pelos participantes durante o evento. O artigo não fará uso de observações feitas pelos participantes na íntegra, pois o trabalho não envolve uma pesquisa de campo ou entrevistas. Apenas apresenta de forma ampla algumas percepções que, a nosso ver, foram recorrentes nas falas dos participantes incentivadas por ferramentas interativas do ambiente Moodle. Para tanto, as autoras organizaram uma série de materiais de estudo envolvendo textos e vídeos. O Moodle foi composto por Fórum de Notícias, Fórum de Apresentação, Material de Apoio (vídeos e textos) e Fórum de Discussão.

No link denominado "Material de Apoio" foram disponibilizados capítulos do livro escrito por Pinto (2005); uma resenha (CORONEL; SILVA, 2016); um texto que trata da temática abordada (SILVA, 2016) e dois vídeos. Um vídeo, gravado pelas proponentes do minicurso, apresentando o conceito de tecnologia e outro vídeo discutindo dados bibliográficos do autor (CABELLO, 2016). 
O referido minicurso teve duração de quatro semanas e foi desenvolvido no mês de outubro de 2016. A interação entre os cursistas ocorreu por intermédio de fóruns interativos. Nesse espaço, os 54 cursistas participantes puderam discutir à respeito do conceito de tecnologia cunhado por Pinto (2005), mediados pelas proponentes do minicurso.

\section{RESULTADOS}

Em linhas gerais, podemos dizer que as discussões sobre a temática proposta para este minicurso foram muito profícuas. Como resultado das interações feitas pelos participantes, percebemos que muitos compreenderam como o autor esboçou o conceito de tecnologia e puderam refletir sobre como o esclarecimento do conceito ou ainda, a falta dele, podem alterar as propostas pedagógicas e o desenvolvimento de cursos ofertados na modalidade a distância. Observamos ainda, por meio das discussões realizadas pelos cursistas nos fóruns de discussões, uma visão da tecnologia como instrumentos físicos e palpáveis. Consideramos que isso se dá em função da influência da mídia em associar tecnologia à aparatos eletrônicos. Com relação à tecnologia na educação, alguns participantes expressaram algumas fragilidades encontradas nas instituições de ensino e na própria formação docente. Dentre elas destacam-se: 1- a organização das escolas; 2- a disponibilidade de recursos financeiros e pedagógico; 3- estrutura curricular; e 4as escassas oportunidades de formação em serviço. Esses apontamentos revelam a necessidade de se ampliar as discussões em torno da função das tecnologias na Educação, com vistas a compreensão de que a utilização dessa, numa perspectiva que favoreça o processo de ensino e de aprendizagem, ultrapassa a decisão docente, mas precede do envolvimento das instituições de ensino como um todo. Assim, conclui-se que os participantes desse minicurso, após seu encerramento, avaliaram a proposta incluindo as discussões e reflexões que dali emergiram como significativas para sua atuação profissional e compreenderam que, conceitualmente, é preciso ampliar o entendimento acerca de termos como tecnologia para além do senso comum e, dessa forma, refletir e agir em práticas educativas que possam transformar a realidade.

\section{DISCUSSÃO}

Ao tomarmos como estudo o livro O Conceito de Tecnologia, Volume I, de Álvaro Vieira Pinto, cumpre ressaltar, primeiramente, que trata-se de uma obra póstuma. Este livro foi composto por meio de um manuscrito de 1140 páginas encontrado pela irmã do advogado responsável pelos bens de Álvaro e de sua esposa.

O autor, mesmo tendo suas reflexões referentes às tecnologias realizadas nos anos de 1970, explicita que o homem, enquanto um antropóide superior e com a capacidade de pensar, apresenta a capacidade de maravilhar-se com as suas criações de artefatos que possam lhe assegurar condições de conforto, segurança e dominação. Nesse sentido, a capacidade de maravilhamento "é um dote fundamentalmente histórico, tendo por determinante o desenvolvimento das forças produtivas" (PINTO, 2005, p.39).

Sua capacidade de transformar a partir do que a natureza dispõe e o uso que se faz dela decorre historicamente da percepção ideológica que se tem da realidade vivida. Isso se dá sob o nome de ciência. O grau de maravilhamento ocorre a partir do nível de domínio da natureza pelo humano e o grau de constituição da sociedade.

Esse fator, quando desvinculado do contexto histórico, torna-se causa da superficialidade na compreensão, por um sistema lógico, dos aspectos que envolvem o processo da natureza e da existência humana.

Pinto (2005) exemplifica que a adoção das tecnologias e o conforto que elas produzem levam à sua naturalização produzindo uma consciência coletiva de que não pensemos a vida sem elas. Como exemplo, traz o uso da energia elétrica entre outros, e que sem a sua presença estaríamos voltando à normalidade antiga. 
O autor recusa a expressão "era tecnológica" que está sendo recorrentemente enaltecida, pois alega que essa terminologia pretende fazer-nos crer que estamos vivendo numa era extraordinária. Contudo, defende que o homem não seria humano se não vivesse sempre numa era tecnológica. No entanto, o que a atual era se difere das demais, é o ritmo acelerado das inovações.

Importante destacar que a valoração das inovações tecnológicas converte-se em ideologia, que por sua vez torna-se um procedimento favorável às classes sociais que desfrutam da posse desses instrumentos, bens, objetos de conforto e entretenimento que a ciência do tempo lhes põe ao dispor (PINTO, 2005).

O filósofo ainda faz um alerta quanto ao processo de transformação que está ocorrendo. Está sendo enaltecida a capacidade técnica de criação do homem a qual, passa a ser vista como fonte de credibilidade, respeito e admiração. A evolução tecnológica, passa a ser percebida também, como um mecanismo natural e inevitável do progresso, isto é, os países que apresentam desenvolvimento tecnológico adquirem essa cobertura moral na qual acabam por desconsiderar as evoluções até então ocorridas historicamente. A atual evolução só está ocorrendo devido ao aproveitamento dos conhecimentos, das pesquisas realizadas e das conquistas técnicas qualitativas herdadas do passado. Por vezes, é esquecido que o verdadeiro criador é o ser humano e não o mundo, perdendo de vista e com facilidade, a noção biológica e histórica.

Diante desse processo, promove-se então uma seleção natural entre os mais fortes considerados como países desenvolvidos em detrimentos daqueles que não desenvolvem-se tecnologicamente, os periféricos. Para alguns países, cabe a criação das tecnologias e para outros, o seu consumo ainda que, de forma passiva e lenta, em alguns casos, envelhecidas e ultrapassadas pelas realizações verdadeiramente vanguardistas. Incute-se na mentalidade das pessoas que vivem nesses países, o caráter imperioso e irremissível dessa situação. Enquanto aos países periféricos resta ainda, a fabricação da tecnologia que produz uma falsa crença de estarem fazendo parte da inserção ao mundo tecnológico.

O autor ressalta que não devemos ser reprodutores de ideologias que julgam a técnica como instrumento característico de desumanização do homem, mas como a técnica criada pelo homem e a serviço dele. Só ocorre o processo de desumanização quando o "homem perde a capacidade de ser o produtor, degradando-se na condição de mero consumidor, da qual o tipo de aproveitador do trabalho alheio é a variedade mais frequente (PINTO, 2005, p. 61)".

Pinto $(2005$, p.47) enfatiza veementemente que "Jamais houve alguma época não historicamente extraordinária", visto que todas as épocas apresentam seu desenvolvimento tecnológico e suas criações. Como toda máquina ou criação corporifica uma técnica previamente concebida não se deve, portanto, separar metafisicamente a máquina e a técnica. A máquina representa uma das manifestações do processo de criação do homem por si mesmo. É a capacidade que o ser humano desenvolveu para se projetar. O humano possui faculdades exclusivamente humanas, a linguagem e a capacidade de projetar. Essa função de produtor é o que o qualifica como animal superior (PINTO, 2005).

Pinto (2005) ressalta que ao analisar o desenvolvimento da espécie, o ser humano e a sua história passam a constituir o que ele chama de social. Isso se refere às modificações do mundo determinadas pelas intervenções provocadas pelo humano e sua capacidade de projetar e criar.

Com base na explicitação do conceito de tecnologia elaborado Pinto (2005), foi possível verificar durante o minicurso intitulado "O conceito de tecnologia na perspectiva de Álvaro Vieira Pinto", que a ideia inicial dos cursistas sobre o conceito de tecnologia se relacionava diretamente com objetos e aparados tecnológicos. Pudemos constatar este fato por meio das afirmações realizadas nos fóruns de discussão, os quais relatavam que a tecnologia é utilizada como recurso para facilitar o dia a dia, de forma que torna o trabalho e as atividades cotidianas mais fáceis. 
Com relação à compreensão da tecnologia ligada a Educação encontramos afirmações que diziam que são os recursos utilizados pelo professor para ministrar as aulas, como lápis, computador, alfabeto, projetor multimídia, por exemplo. Também se observou nas respostas dos cursistas uma visão mais ampliada do conceito de tecnologia ao citarem que a tecnologia é desenvolvida a partir das necessidades humanas, com a finalidade da satisfação destas necessidades. Ainda destacaram que todos os seres humanos historicamente situados, desenvolveram tecnologia, transformando a sua realidade e a sociedade em que viviam.

Em termos de compreensão da tecnologia direcionada à aprendizagem encontramos relatos que afirmavam que a utilização da tecnologia deixa as aulas mais lúdicas e favorecem o processo de aprendizagem. Também foram apontados alguns motivos para a dificuldade de se pensar a utilização das tecnologias no ambiente escolar, como a falta de formação do professor para pensar e utilizar a tecnologia nas suas aulas.

Ao analisarmos as respostas dos cursistas, observamos a necessidade de um aprofundamento na discussão da organização das práticas escolares, da cultura das escolas, pois consideramos que a utilização das diversas tecnologias criadas pelos seres humanos só ocorrerá de maneira satisfatória, na medida em que reconhecermos a tecnologia como expressão do conhecimento e não como produtora de conhecimento.

\section{CONCLUSÃO}

Nesse artigo objetivamos apresentar algumas considerações acerca do conceito de tecnologia elaborado por Álvaro Vieira Pinto (1909-1987), com base no livro intitulado "O Conceito de Tecnologia", Volume I (PINTO, 2005), bem como relatar a oferta de um minicurso a professores, tutores, acadêmicos da graduação e de pós-graduação, com a referida temática.

O estudo dessa obra nos possibilita uma compreensão na perspectiva do autor relativa à tecnologia enquanto criação do humano, a partir da capacidade de projetar recorrendo aos recursos disponíveis pela natureza. Essa capacidade de projetar, de utilizá-la seja para o bem ou para o mal é o que diferencia como um ser antropóide superior.

As tecnologias devem ser compreendidas aliadas ao contexto histórico vigente, pois em cada período histórico tiveram sua importância e o ser humano, decorrente do seu uso, alterou seu comportamento social, porém, não houve alteração na divisão do poder permanecendo e acentuando, o já estabelecido, domínio dos países ricos em detrimento dos países periféricos.

Quanto à percepção dos cursistas no estudo da referida obra, pudemos observar que a relação estabelecida com a tecnologia é como uma ferramenta que facilita a vida dos seres humanos, como algo concreto, palpável, visível aos olhos e ao alcance das mãos. Essa percepção é projetada na forma como se concebe a tecnologia na educação, como recursos tangíveis, que podem ser utilizados por professores e alunos e que em alguns casos substitui a tecnologia anterior, como é o caso do projetor multimídia. No entanto, os cursistas sentiram dificuldades em conceber a tecnologia na educação para além destes limites.

$\mathrm{Na}$ discussão da tecnologia no processo de aprendizagem os cursistas explicitam a utilização da tecnologia como um recurso lúdico, no entanto, este pensamento não está desvinculado dos limites que são estabelecidos para a utilização da tecnologia na educação, conforme explicitado acima. Neste sentido, nos questionamos: a ludicidade é atribuída a utilização do projetor multimídia em sala de aula em detrimento do quadro negro?

E por fim a recorrente discussão da falta de formação dos professores para pensar a tecnologia e utilizá-la no processo de ensino. Com relação ao primeiro ponto, concordamos plenamente, uma vez que, de forma geral, falta formações que estimulem e incitem os professores a pensarem sobre a utilização destes recursos, que os desafiem a sair da zona de conforto. Já no segundo ponto, temos que concordar que esta discussão já está vencida, uma vez 
que a tecnologia se faz presente no nosso cotidiano, então não há desculpas para aprendê-la e utilizá-la.

Caberia aqui, neste contexto, não a discussão da falta de formação dos professores para manuseio da tecnologia, mas sim a discussão da falta de políticas públicas que possibilitem o acesso e utilização das tecnologias nas instituições de ensino, uma vez que, como sabemos a maior parte das escolas não possuem sequer infraestrutura e equipamentos. Isso seria o mínimo para que iniciemos uma discussão a respeito da formação para utilização das mesmas.

Consideramos, por fim, que esse intelectual trata de uma questão relevante e atual. Avaliamos que trazer à tona tal discussão, por meio de um minicurso foi muito significativo e necessário, uma vez que há predomínio de conhecimentos rasos e de senso comum. A compreensão do conceito de tecnologia pode contribuir para reflexões e ações mais coerentes nem nosso dia a dia, principalmente no âmbito da educação.

\section{REFERÊNCIAS}

CABELLO, C. Videobiografia Álvaro Vieira Pinto. 7'03". Disponível em: https://www.youtube.com/watch?v=IrZOJMnkK8g. Acesso em: 6 jul. 2016.

CORONEL, D. A.; SILVA, J. M. A. da. O conceito de tecnologia, Álvaro Vieira Pinto. Disponível em: https://www.researchgate.net/publication/287438802_O_conceito_de_tecnologia_por_Alvaro_Vi era_Pinto. Acesso em: 12 jul. 2016.

SILVA, G. C. e. Tecnologia, educação e tecnocentrismo: as contribuições de Álvaro Vieira Pinto. Disponível em: http://www.scielo.br/pdf/rbeped/v94n238/a10v94n238.pdf. Acesso em: 10 ago. 2016.

PINTO, Á. V. O conceito de tecnologia. Rio de Janeiro: Contraponto, v. 1, 2005. 